\title{
Knowledge, attitude and practice of pharmacists regarding dietary supplements in Riyadh, Saudi Arabia
}

\author{
Qasem Ali Bahri ${ }^{1}$, Ageeli Rabea Mussa R ${ }^{1}$, Ashwaq Abdulhamid alahmadi ${ }^{2}$ \\ ${ }^{1}$ king fahad central hospital, ${ }^{2} \mathrm{Al}$ noor specialist hospital \\ Corresponding author: Qasem Ali Bahri, email:Qassem91.qb@gmail.com,mobile:00966531579899
}

\begin{abstract}
Background: Dietary supplements are a term that refers to several products such as vitamins, minerals and high energy compounds. Using these supplements is very common among individuals in different communities. Pharmacists had important effect on the public health as they help individuals to choose supplements and provide them with information.
\end{abstract}

Aim: To assess knowledge, attitude and practice of pharmacists toward dietary supplements.

Methods: This study is cross sectional, it was conducted on pharmacists in Riyadh region, Saudi Arabia, using an online survey.

Results: There were 500 pharmacists included in this study, $75.4 \%$ had good knowledge, $71.6 \%$ had positive attitude and $50.8 \%$ had good practice. Both of knowledge and attitude were significantly affected by age, experience years and level of education, whereas practice was significantly affected by experience years only (P-value $<0.05)$.

Conclusion: There were good knowledge and positive attitude toward dietary supplements among pharmacists, however close percents had either good or bad practice.

Keywords: Dietary supplements, Pharmacists, KAP.

\section{Introduction:}

Dietary supplements involve several products such as minerals, vitamins, high energy compounds and herbal products [1]. Dietary supplements aren't considered part of conventional medicines [2]. Using these supplements is affected by characteristics of individuals and the diseases they suffer [3]. Individuals who seek for weight loss or weight gain use supplements commonly [4]. These supplements are sold very widely in pharmacy, although there is no specific approval or scientific usage for these products [5]. It was reported by American Society of nutrition that dietary supplements are used by large proportion of population in their routine life ${ }^{[6]}$.

Dietary supplements or complementary alternative medicine (CAM) is an issue that pharmacists face [7]. Pharmacists are most important interface of the medicine field ${ }^{[7]}$, they have great impact on public health ${ }^{[8]}$ as they help patients and individuals to choose dietary supplements safely [9]. Also, they can provide information to patients regarding their interaction with conventional medicine ${ }^{[10]}$. It was found that persons who consume dietary supplements ask pharmacists about theses supplements [11]. It was found in Australia that $87 \%$ of consumers thought that pharmacists were able to know the effectiveness of dietary supplements [12]. Pharmacists should have enough knowledge about the advantages and risks of each treatment method [13]. This study was performed to investigate the knowledge, attitude and practice of pharmacists toward dietary supplements.

\section{Subjects and methods:}

Subjects and study design:

This is cross sectional study which was conducted on pharmacists in Riyadh, Saudi Arabia, in the period from June 2018 to August 2018. The study was performed using an online survey which included 4 parts to assess demographics of participants, knowledge, attitude and practice regarding dietary supplements.

\section{Statistical analysis:}

Software package for statistical analysis version 20 was used to analyze the data. Frequency and percent were used for categorical variables. Chi-square was used to find associations and correlations between different variables. P-value $<0.05$ was considered significant.

\section{Results:}

The present study included 500 pharmacists from Riyadh city, Saudi Arabia. Males were more dominant 350(70\%) than females $150(30 \%)$, and those with age less than 25 years old were more dominant 170(34\%) among other age groups. Those with experience less 
than 5 years were $178(35.6 \%)$, followed by those with $5-10$ years $122(24.4 \%)$ then those with experience of 11-20 years and $>20$ years old $100(20 \%)$ for each group. $400(80 \%)$ of participants reported that their monthly income was enough. Majority of pharmacists $310(62 \%)$ reported having bachelor in pharmacy, while $78(15.6 \%)$ reported having diploma, whereas $73(14.6 \%)$ and $39(7.8 \%)$ reported having master and doctor degree in pharmacy respectively,( table1).

Table1: Characteristics of pharmacists

\begin{tabular}{|l|l|}
\hline \hline Characteristics & $\mathrm{N}(\%)$ \\
\hline Gender & $350(70 \%)$ \\
Female & $150(30 \%)$ \\
\hline Age & \\
$<25$ & $170(34 \%)$ \\
$25-35$ & $130(26 \%)$ \\
$36-45$ & $112(22.4 \%)$ \\
$>45$ & $88(17.6 \%)$ \\
\hline Experience & \\
$<5$ years & $178(35.6 \%)$ \\
$5-10$ years & $122(24.4 \%)$ \\
$11-20$ years & $100(20 \%)$ \\
$>20$ years & $100(20 \%)$ \\
\hline Monthly income & \\
Enough & $400(80 \%)$ \\
Not enough & $100(20 \%)$ \\
\hline Level of education & \\
Bachelor of science in pharmacy & $310(62 \%)$ \\
Diploma in pharmacy & $78(15.6 \%)$ \\
Master of science in pharmacy & $73(14.6 \%)$ \\
Doctor of pharmacy & $39(7.8 \%)$ \\
\hline
\end{tabular}

The levels of knowledge, attitude and practice are shown in figure1. There were 377(75.4\%) found to have good knowledge, whereas $123(24.6 \%)$ had poor knowledge. Regarding attitude, positive attitude was expressed by
$358(71.6 \%)$, while negative attitude was expressed by $142(28.4 \%)$. Close percents were obtained regarding good and bad practice $254(50.8 \%)$ and $246(49.2 \%)$ respectively.

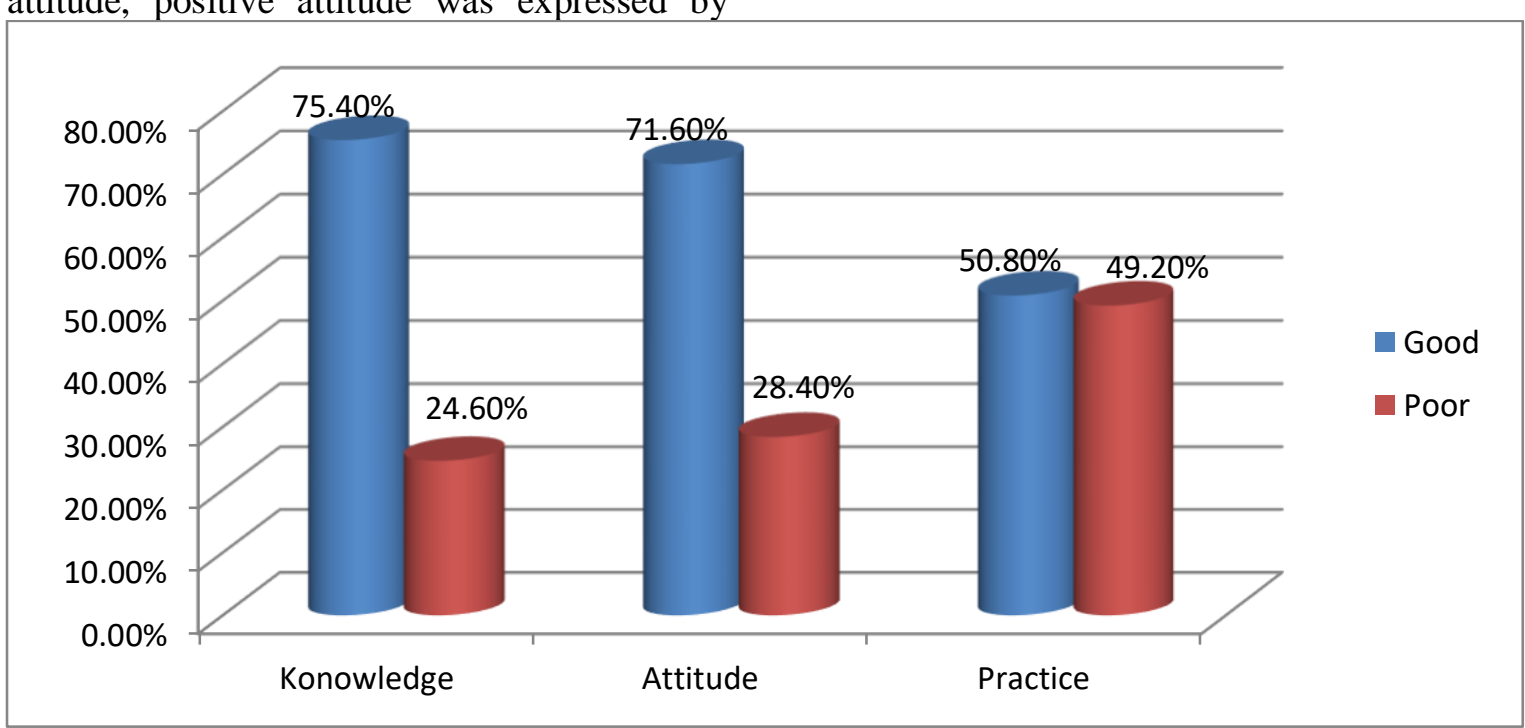

Fig1: Knowledge, attitude and practice of pharmacists

$\underline{\text { (for attitude; poor=negative, for practice, poor=bad) }}$

The correlations between different characteristics and knowledge, attitude and practice are shown in table2. The level of knowledge was significantly affected by age (Pvalue $=0.02)$, experience years $(\mathrm{P}$-value $=0.001)$ and level of education $(\mathrm{P}-\mathrm{value}=0.01)$. Those 
with age of 25-35 years old, experience years of less than 5 years and had diploma in pharmacy tended to have good knowledge than other participants. The same was found regarding attitude, where attitude was significantly influenced by age $(\mathrm{P}$-value $=0.01)$, experience years $(\mathrm{P}$-value $=0.002)$ and level of education
(P-value $=0.006)$. Positive attitude was more expressed by participants with age of 25-35 years old, experience years of less than 5 years and had diploma. Practice was only influenced by experience years $(\mathrm{P}$-value $=0.05)$, where those with experience years of 5-10 years were more prone to have good practice.

Table2: Correlations between demographics of pharmacists and knowledge, attitude and practice

\begin{tabular}{|c|c|c|c|c|c|c|}
\hline \multirow[t]{2}{*}{ Characteristics } & \multicolumn{2}{|l|}{$\begin{array}{l}\text { Knowledge } \\
\mathrm{N}(\%)\end{array}$} & \multicolumn{2}{|l|}{$\begin{array}{l}\text { Attitude } \\
\mathrm{N}(\%)\end{array}$} & \multicolumn{2}{|l|}{$\begin{array}{l}\text { Practice } \\
\mathrm{N}(\%)\end{array}$} \\
\hline & $\begin{array}{l}\text { Good } \\
377\end{array}$ & $\begin{array}{l}\text { Poor } \\
123\end{array}$ & $\begin{array}{l}\text { Positive } \\
358\end{array}$ & $\begin{array}{l}\text { Negative } \\
142\end{array}$ & $\begin{array}{l}\text { Good } \\
254\end{array}$ & $\begin{array}{l}\text { Bad } \\
246 \\
\end{array}$ \\
\hline \multirow{2}{*}{$\begin{array}{l}\text { Gender } \\
\text { Male } \\
\text { Female } \\
\text { P-value }\end{array}$} & $\begin{array}{l}297(59.4 \%) \\
80(16 \%)\end{array}$ & $\begin{array}{l}53(10.6 \%) \\
70(14 \%)\end{array}$ & $\begin{array}{l}293(85.6 \%) \\
65(13 \%)\end{array}$ & $\begin{array}{l}57(11.4 \%) \\
85(17 \%)\end{array}$ & $\begin{array}{l}179(35.8 \%) \\
75(15 \%)\end{array}$ & $\begin{array}{l}171(34.2 \%) \\
75(15 \%)\end{array}$ \\
\hline & \multicolumn{2}{|l|}{0.5} & \multicolumn{2}{|l|}{0.9} & \multicolumn{2}{|l|}{0.1} \\
\hline \multirow[t]{2}{*}{$\begin{array}{l}\text { Age } \\
<25 \\
25-35 \\
36-45 \\
>45 \\
\text { P-value }\end{array}$} & $\begin{array}{l}100(20 \%) \\
112(22.4 \%) \\
100(20 \%) \\
65(13 \%) \\
\end{array}$ & $\begin{array}{l}70(14 \%) \\
18(3.6 \%) \\
12(2.4 \%) \\
23(4.6 \%)\end{array}$ & $\begin{array}{l}149(29.8 \%) \\
100(20 \%) \\
79(15.8 \%) \\
30(6 \%)\end{array}$ & $\begin{array}{l}21(4.2 \%) \\
30(6 \%) \\
33(6.6 \%) \\
58(11.6 \%) \\
\end{array}$ & $\begin{array}{l}85(17 \%) \\
65(13 \%) \\
52(10.4 \%) \\
52(10.4 \%)\end{array}$ & $\begin{array}{l}85(17 \%) \\
65(13 \%) \\
60(12 \%) \\
36(7.2 \%)\end{array}$ \\
\hline & \multicolumn{2}{|l|}{0.02} & \multicolumn{2}{|l|}{0.01} & \multicolumn{2}{|l|}{0.09} \\
\hline \multirow[t]{2}{*}{$\begin{array}{l}\text { Experience } \\
<5 \text { years } \\
5-10 \text { years } \\
11-20 \text { years } \\
>20 \text { years } \\
\text { P-value }\end{array}$} & $\begin{array}{l}114(22.8 \%) \\
102(20.4 \%) \\
77(15.4 \%) \\
84(16.8 \%)\end{array}$ & $\begin{array}{l}64(12.8 \%) \\
20(4 \%) \\
23(4.6 \%) \\
16(3.2 \%) \\
\end{array}$ & $\begin{array}{l}157(31.4 \%) \\
100(20 \%) \\
59(11.8 \%) \\
42(8.4 \%)\end{array}$ & $\begin{array}{l}21(4.2 \%) \\
22(4.4 \%) \\
41(8.2 \%) \\
58(11.6 \%)\end{array}$ & $\begin{array}{l}104(20.8 \%) \\
105(21 \%) \\
25(5 \%) \\
20(4 \%)\end{array}$ & $\begin{array}{l}74(14.8 \%) \\
17(3.4 \%) \\
75(15 \%) \\
80(16 \%)\end{array}$ \\
\hline & \multicolumn{2}{|l|}{0.001} & \multicolumn{2}{|l|}{0.002} & \multicolumn{2}{|l|}{0.005} \\
\hline \multirow{2}{*}{$\begin{array}{l}\text { Monthly income } \\
\text { Enough } \\
\text { Not enough } \\
\text { P-value }\end{array}$} & $\begin{array}{l}327(65.4 \%) \\
50(10 \%)\end{array}$ & $\begin{array}{l}73(14.6 \%) \\
50(10 \%)\end{array}$ & $\begin{array}{l}300(60 \%) \\
58(11.6 \%)\end{array}$ & $\begin{array}{l}100(20 \%) \\
42(8.4 \%)\end{array}$ & $\begin{array}{l}255(51 \%) \\
58(11.6 \%)\end{array}$ & $\begin{array}{l}145(29 \%) \\
42(8.4 \%)\end{array}$ \\
\hline & \multicolumn{2}{|l|}{0.7} & \multicolumn{2}{|l|}{0.8} & \multicolumn{2}{|l|}{0.4} \\
\hline $\begin{array}{l}\text { Level of education } \\
\text { Diploma in pharmacy } \\
\text { Bachelor of science in } \\
\text { pharmacy } \\
\text { Master of science in } \\
\text { pharmacy } \\
\text { Doctor of pharmacy }\end{array}$ & $\begin{array}{l}201(40.2 \%) \\
68(13.6 \%) \\
70(14 \%) \\
38(7.6 \%)\end{array}$ & $\begin{array}{l}109(21.8 \%) \\
10(2 \%) \\
3(0.6 \%) \\
1(0.2 \%)\end{array}$ & $\begin{array}{l}259(51.8 \%) \\
48(9.6 \%) \\
30(6 \%) \\
21(4.2 \%)\end{array}$ & $\begin{array}{l}51(10.2 \%) \\
30(6 \%) \\
43(8.6 \%) \\
18(3.6 \%)\end{array}$ & $\begin{array}{l}154(30.8 \%) \\
39(7.8 \%) \\
38(7.6 \%) \\
23(4.6 \%)\end{array}$ & $\begin{array}{l}156(31.2 \%) \\
39(7.8 \%) \\
35(7 \%) \\
16(3.2 \%)\end{array}$ \\
\hline P-value & \multicolumn{2}{|l|}{0.01} & \multicolumn{2}{|l|}{0.006} & \multicolumn{2}{|l|}{0.7} \\
\hline
\end{tabular}

\section{Discussion:}

The current study included 500 pharmacists, by assessing their knowledge, attitude and practice regarding dietary supplements. It was found that good knowledge was present among $75.4 \%$ and $71.6 \%$ showed positive attitude toward dietary supplements, whereas only $50.8 \%$ had good practice. It was reported in 2007 that the positive attitude was related to the good knowledge about dietary supplements ${ }^{[14]}$. In a previous Saudi study ${ }^{[7]}$, it was found that there was lack of information. A study carried by Clauson et al. [11] showed that there was inadequate knowledge about dietary supplements of pharmacists. In agreement with our findings, it was reported by MehrAlian et al
[15] that pharmacists with higher knowledge had more positive attitude and better performance toward the supplements, the same was reported by Iranian study [9], however in our study there was high percent of pharmacists had good knowledge and positive attitude, whereas performance wasn't so good. A study done by Portyansky [16] demonstrated that most pharmacists had positive attitude toward dietary supplements and this conclusion is in agreement with our findings. A study was conducted in Canada showed that $63 \%$ of pharmacists had positive attitude toward alternative treatment [17]. On the contrary, studies was undertaken in USA found that $50 \%$ 
of pharmacists had negative attitude toward dietary supplements and believed they weren't safe [18, 19]. The differences among these different results studies could be attributed to the differences in the community, level of education and awareness degree among the studied groups. The current study showed that knowledge of pharmacists was significantly associated with age, years of experience and education level, pharmacists with higher knowledge were those of age of 25-35 years old, experience less than 5 years and having diploma in pharmacy. Pharmacists with experience less than 5 years were more prone to have better knowledge and this can be explained by their scientific experience which increase and improve their knowledge, also availability of time that enabled them to read more than participants with older experience, also those young less experienced pharmacists read the more recent researches than older ones who may prefer holding on old information. It was demonstrated in previous Saudi study that knowledge was affected by gender ${ }^{[7]}$ and this was in contrast to our findings as sex had no influence on level of knowledge among our participants. Our study found no influence of sex on KAP of pharmacists. It was reported in Iranian study [9] that knowledge and performance weren't affected by gender, whereas attitude was affected by gender and females had more positive attitude toward dietary supplements. Also, it was reported that knowledge wasn't affected by age, education and work experience and regarding performance, gender had no significant effect on performance ${ }^{[9]}$. Another study reported that age and work experience didn't influence knowledge, whereas gender, position and education affected knowledge significantly [15]. Regarding attitude, the current study revealed that attitude of pharmacists was significantly affected by their age, experience and education level. Pharmacists with age less than 25 years tended to have positive attitude among other age groups, also those with experience less than 5 years and had diploma in pharmacy tended to have positive attitude compared to other pharmacists. Practice in our study was affected only by experience years of the pharmacists; those with age of 5-10 years had more practice than other participants. Gender was found to have no effect on both attitude and practice in previous Saudi study [7]. This finding is in agreement with our results, however older age participants in the previous Saudi study ${ }^{[7]}$ were found to be more familiar with this type of treatment in comparison with younger age, and however, our results were not comparable with this conclusion.

\section{Conclusion:}

There were good knowledge and positive attitude toward dietary supplements, whereas there was poor practice. Additional studies are required to justify our conclusions and add more information and knowledge to deal with these topics of studies.

\section{References:}

1-Petróczi A, Naughton DP, Pearce G, Bailey R, Bloodworth A, McNamee $M(2008)$ : Nutritional supplement use by elite ytopics of these topics of studies oung UK athletes: Fallacies of advice regarding efficacy. J Int Soc Sports Nutr.,5:9-22.

2-Sura S, Chabria A and Sansgiry SS(2010): Pharmacy students knowledge and attitude towards herbal medications. Int. J. Pharm. Pract.,8: 1-7.

3-Yi HH, Park HA, Kang JH, Kim KW, Cho YG, Song HR et al.(2009): What types of dietary supplements are used in Korea? Korean J Fam Med.,30(12):934-43.

4-Pillitteri JL, Shiffman S, Rohay JM, Harkins AM, Burton SL, Wadden TA(2012): Use of dietary supplements for weight loss in the United States: Results of a national survey. Obesity,61:790-6.

5-Eisenberg DM, Davis RB, Ettner SL, Appel S, Wilkey S, Van Rompay $\mathrm{M}$ et al.(1998): Trends in alternative medicine use in the United States, 1990-1997: results of a follow-up national survey. Jama.,280:15691575.

6-Bailey RL, Gahche JJ, Lentino CV, Dwyer JT, Engel JS, Thomas PR, Betz JM, Sempos CT, Picciano MF(2010): Dietary supplement use in the United States 2003-2006, The Journal of nutrition,1: 110.

7-Safar Almalki M, Abdullrhman Khobrani A, Thamir Alotaibi F, Abdullah Aljabri H(2018): Knowledge, Attitude and Practice of Pharmacists Regarding Dietary Supplements. Egyptian Journal of Hospital Medicine, 1;70(7). 8-Foroughi Moghadam MJ, Peiravian F, Naderi A, Rajabzadeh $A$ and Rasekh HR(2014): An analysis of job satisfaction among iranian pharmacists through various job characteristics. Iran. J. Pharm. Res.,13: 10871096. 
9-Bastani P, Jooybar M, Ahmadzadeh M, Samadbeik M(2017): Community pharmacybased survey on pharmacists' knowledge, attitude, and performance regarding dietary supplements: Evidence from South of Iran. Natl J Physiol Pharm Pharmacol.,7(4):396-402.

10-Boon H(2005): CAM and pharmacists: Challenge or opportunity? Focus Altern Complement Ther.,10(2):89-91.

11-Clauson KA, McQueen CE, Shields KM, Bryant PJ(2003): Knowledge and attitudes of pharmacists in Missouri regarding natural products. Am J Pharm Educ.,67(2):1-9.

12-Braun LA, Tiralongo E, Wilkinson JM, Spitzer O, Bailey M, Poole S et al.(2010): Perceptions, use and attitudes of pharmacy customers on complementary medicines and pharmacy practice. BMC Complement Altern Med.,10:38.

13-Brown JA, Roufogalis BD and Williamson M(2009): Complementary medicines: hospital pharmacists' attitude, knowledge and information seeking behaviour. Journal of Pharmacy Practice and Research, 39:281-285.

14-Misra R(2017): Knowledge, attitudes, and label use among college students, 107(12),
Journal of the American Dietetic Association, 1:107(12): 2130-4.

15-Mehralian G, Yousefi N, Hashemian F, Maleksabet H(2014): Knowledge, attitude and practice of pharmacists regarding dietary supplements: A community pharmacy-based survey in Tehran. Iran $\mathbf{J}$ Pharm Res.,13(4):1457-65.

16-Portyansky E(1998): Alternative medicine: How bountiful is the harvest? Where does it fit in the pharmacy? Drug Top.,142(7):44-50.

17-Montbriand MJ(2000): Alternative therapies health professionals attitudes. Can Nurse,96(3):22-6.

18-Dunn JD, Cannon HE, Lewis T, ShaneMcWhorter L(2005): Development of a complementary and alternative medicine (CAM) pharmacy and therapeutics (P\&T) subcommittee and CAM guide for providers. J Manag Care Pharm.,11(3):252-8.

19-Welna EM, Hadsall RS, Schommer JC(2003): Pharmacists' personal use, professional practice behaviors, and perceptions regarding herbal and other natural products. J Am Pharm Assoc.,43(5):602-11. 